\title{
A rare case of primary vaginal carcinoma in prolapsed uterus
}

\author{
Sanjay C., Bharathi Rao*, Sharadha Rai
}

Department of Obstetrics and Gynaecology, KMC, Maniapal Academy of Higher Education, Mangalore, Karnataka, India

Received: 24 October 2020

Accepted: 18 December 2020

\section{*Correspondence:}

Dr. Bharathi Rao,

E-mail: Statisticsclinic2018@gmail.com

Copyright: (c) the author(s), publisher and licensee Medip Academy. This is an open-access article distributed under the terms of the Creative Commons Attribution Non-Commercial License, which permits unrestricted non-commercial use, distribution, and reproduction in any medium, provided the original work is properly cited.

\begin{abstract}
Primary carcinoma is rare in gynaecological neoplasia. Vaginal carcinoma in prolapse uterus is extremely rare. We hereby present a case of 55-year-old P3L3 postmenopausal woman with complete uterine prolapse with fungating growth of $6 \times 8 \mathrm{~cm}$ with two decubitus ulcers of $1 \times 1 \mathrm{~cm}$. Marginal biopsy showed well-differentiated squamous cell carcinoma of vagina. Investigation was done showed no metastasis. Patient was diagnosed with stage 2 disease. Patient underwent 5 cycles of chemotherapy with 2 cycles of radiotherapy and is being followed up. The importance of biopsy of ulcer in cases of UV prolapse in order to exclude malignancy to avoid incomplete treatment has been illustrated through this case. The need of careful evaluation of vaginal erosions in pelvic organ prolapse has been highlighted. As there is lack of well-defined treatment protocols for vaginal cancer with concurrent prolapse, the case also underlines the importance of a multidisciplinary approach involving gynaecological oncology, urogynaecology, medical oncology, surgical oncology and radiation oncology.
\end{abstract}

Keywords: Cancer, Prolapse, Uterus, Squamous cell carcinoma

\section{INTRODUCTION}

Malignant diseases of the vagina are either primary vaginal cancers or metastatic cancers from adjacent or distant organs. Primary vaginal cancers are defined as arising solely from the vagina, with no involvement of the external cervical OS proximally or the vulva distally. The importance of this definition lies in the different clinical approaches to the treatment of upper and lower vaginal cancer. ${ }^{1}$

According to the international federation of gynaecology and obstetrics (FIGO), a vaginal lesion involving the external OS of the cervix should be considered cervical cancer and treated as such; a tumor involving both the vulva and the vagina should be considered vulvar cancer.
Although primary vaginal carcinoma is a rare gynaecologic malignancy, its impact on women's health should not be underestimated, especially when considering the demographic increase in elderly women. As more women survive past age 60 years, physicians need to consider the likelihood that more women will present with vaginal cancer. ${ }^{2}$

Primary vaginal carcinoma is a rare disease which accounts for $1-2 \%$ of all gynaecological malignancies., Its presence in association with complete uterovaginal prolapse is an even rarer occurrence. Until now less than 10 cases have been reported in literature. ${ }^{3-5}$ It is most commonly seen at the posterior upper two-third of vagina. Most women present in the $6^{\text {th }}$ to $7^{\text {th }}$ decade of life. ${ }^{3,4}$ The growth may be ulcerative or fungating. Patients may be asymptomatic or present with vaginal 
bleeding. Owing to the rarity of this condition, treatment guidelines are yet to be standardised.

\section{CASE REPORT}

Mrs. A, 55-year-old P3L3 postmenopausal lady presented to Lady Goshen hospital on 18/12/19 with history of a mass descending from the vagina for 4 months and bleeding per vagina for 2 days. On examination, complete uterovaginal prolapse (procidentia) was noted, with a fungating growth of $6 \times 8 \mathrm{~cm}$ seen on the right lateral aspect. 2 ulcers were noted on the prolapsed vagina, measuring $1 \times 1 \mathrm{~cm}$ each, situated away from cervix. The ulcers had everted margins, an indurated base, and bled on touch. Per rectal examination was normal. MRI was done which showed procidentia with exophytic growth in the right lateral region of vagina measuring $4.9 \times 2.3 \times 5.8$ $\mathrm{cm}$ with no involvement of the parametrium, cervix, bladder, bowel or rectum. No evidence of any enlarged lymph nodes. Pap smear was negative for intraepithelial lesion or malignancy. Marginal biopsy was taken and sent for histopathology which later confirmed a well differentiated squamous cell carcinoma of the vagina. Patient was diagnosed with stage 2 vaginal carcinoma due to involvement of paravaginal tissue. Planned for 5 cycles of carboplatin chemotherapy and interstitial brachytherapy with 6 cycles per fraction total of 3 fractions radiotherapy. Patient received 5 cycles of chemotherapy with carboplatin and received only 2 fractions till now. No metastasis is seen during her 8 months follow up. Patient is doing well.

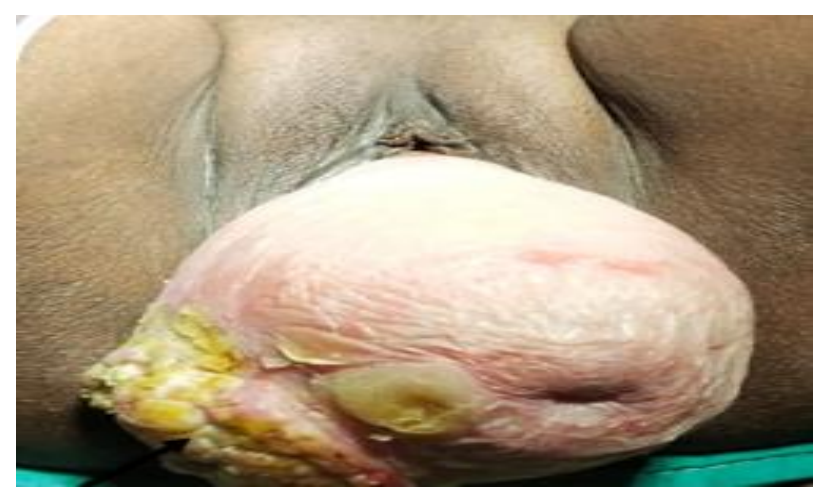

Figure 1: Fungating growth.

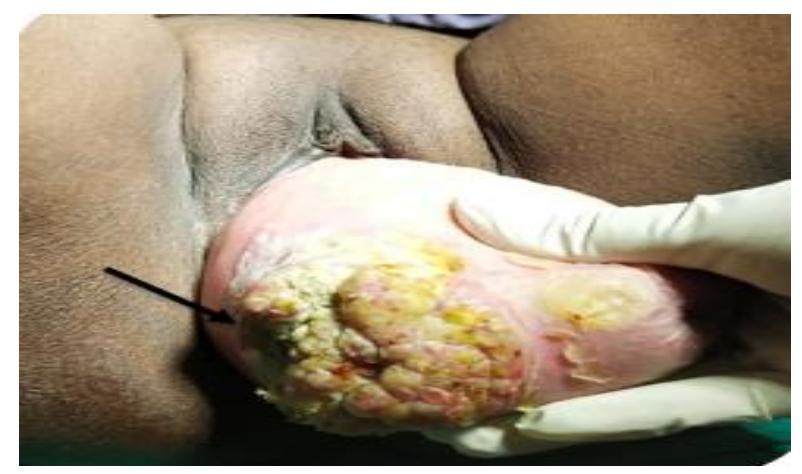

Figure 2: Ulcer.

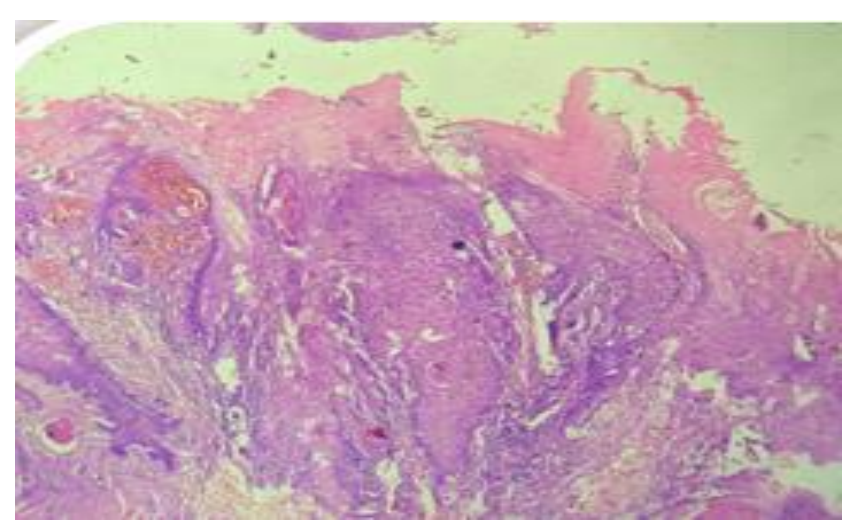

Figure 3: Well, differentiated squamous cell carcinoma.

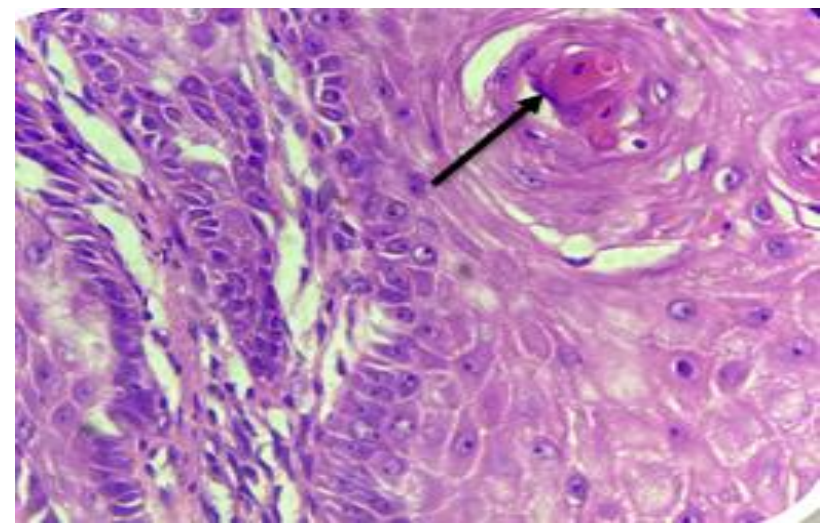

Figure 4: Keratin pearls.

\section{DISCUSSION}

Most vaginal carcinoma are secondary with the primary focus being in the pelvic organs and the perineum in particular the uterus, cervix, bladder, urethra vulva with a spread by lymphatics. Most vaginal carcinoma are squamous cell carcinoma, but melanoma, sarcoma, adenocarcinoma also occur. SCC of vagina constitute $80 \%$ of vaginal carcinoma at age 60-80 years with multiple pregnancy, genital warts, poor genital hygiene, chronic usage of pessary and bacterial and HPV infection, cervical cancer in situ or invasive which was treated previously also being the risk factors. In long standing inflammation, lesion is most commonly seen. One study had conducted biopsy on these ulcerative lesions and identified the most common lesion to be chronic cervicitis at $97.9 \%$ of the study population followed by cervical decubitus ulcer in $13.6 \%$ and carcinoma in situ in $1 \%{ }^{6}$ Hoverer due to the lack of literature there is difficulty and controversy in managing these rare cases. The site, stage and medical comorbidities influence the management. Recommended therapy for vaginal squamous cell carcinoma is radiotherapy, but surgery has satisfactory outcome., ${ }^{7,8}$ Stage 1 surgical excision includes radical hysterectomy, upper vaginectomy with bilateral pelvic lymphadenectomy with or without radiation therapy. Stage 2 to 4 chemoradiation. In sexually active women 
where coitus need to be taken into consideration, surgery has to be considered. In stage 1 , the 5 -year survival rate is $84 \%$ and stage 2 it is $75 \%$. Bottom line being that the stage and size of the disease are the most important prognostic factors.

\section{CONCLUSION}

In the presence of the following features i.e., a foulsmelling discharge, vaginal discharge, vaginal ulcerative lesions in a long-standing pelvic organ prolapse, a biopsy is highly recommended. Vaginal carcinoma with UV prolapses however rare, does occur and an early diagnosis can minimise morbidity and mortality especially since the warning signs often go unrecognised by older women that are frequently affected by this affliction. The modalities of treatment are such a case remain ill defined. A surgical approach combined with radiotherapy may be considered for an early stage whereas in the advanced stages of carcinoma associated with prolapse only chemoradiation should suffice.

\section{Funding: No funding sources}

Conflict of interest: None declared

Ethical approval: Not required

\section{REFERENCES}

1. Creasman WT. Vaginal cancers. Current opinion in obstetrics and gynaecology. 2005;17(1):71-6.
2. FIGO Committee on Gynecologic Oncology. Current FIGO staging for Cancer of the Vagina, Fallopian tube and Gestational trophoblastic neoplasia. Int $\mathbf{J}$ Gyneco Obstet. 2009;105:3-4.

3. Benedet JL, Bender H, Jones H III, Ngan HY, Pecorelli S. FIGO staging classifications and clinical practice guidelines in the management of gynecologic cancers. Int $\mathrm{J}$ Gynaecol Obstet. 2000;70(2):209-62.

4. Donato A. Vaginal cancers. In: Santos CER, Mello ELR, editors. Surgical oncology handbook. Sa o Paulo: Tecmed; 2006;555-60.

5. Iavazzo C, Vorgias G, Vecchini G, Ngan HY, Katsoulis M, Akrivos T. Vaginal carcinoma in a completely prolapsed uterus. A case reports. Arch Gynecol Obstet. 2007;275(6):503-5.

6. Sonkusare S, Vishwanathb, Shetty J, Harikumar S, Murthi P, Muralidharan V. Primary vaginal cancer complicating massive uterine prolapse: A case report. J Cases Obstet Gynecol. 2016;3:92-5.

7. Pratap K, Malhotra N. Tumors of vagina, Jeffcoat's Principles of Gynaecology, $8^{\text {th }}$ Ed, Jaypee brothers. 2014;426.

8. Wang Y, Li Q, Du H, Lv S, Liu H Uterine prolapse complicated by vaginal cancer: a case report and literature review. Gynecol Obstet Invest. 2014;77(2): $141-4$.

Cite this article as: Sanjay C, Rao B, Rai S. A rare case of primary vaginal carcinoma in prolapsed uterus. Int J Reprod Contracept Obstet Gynecol 2021;10:774-6. 